\title{
FRIENDS OR FOES? A THEORETICAL APPROACH TOWARDS CONSTRUCTIVISM, REALISM AND STUDENTS' WELL-BEING VIA ACADEMIC LITERACY PRACTICES
}

\section{O.O. Eybers}

Unit for Academic Literacy

University of Pretoria

Pretoria, South Africa

e-mail: Oscar.Eybers@up.ac.za

\section{ABSTRACT}

The following theoretical analysis aimed to highlight perceived, conceptual differences between constructivist and realist ontologies as meta-theories for approaching students' well-being in institutions of higher learning; specifically, in relation to how first-year students attempt to master academic literacy practices. This theoretical investigation aimed to determine if the two ontologies are theoretically compatible in research endeavours which are geared towards understanding the wellness of first-year students as they attempt to demonstrate mastery of academic literacy practices. The central method applied in this conceptual probe was an interpretive and textual focus on key, local and international perspectives towards student well-being in higher education. The outcome of the analysis revealed that while the two ontologies presented theoretical and conceptual divergences in their framing of first-year, students' well-being as they attempt to master academic literacy practices; mainly, a view of being or reality as mind-emergent or mindindependent, both constructivist and realist ontologies are applicable for comprehending this very phenomenon. This analytical probing concluded by asserting that while constructivism and realism are distinct meta-theories towards understanding the lived experiences and well-being of first-year students who engage in academic literacy practices, they need not be perceived as theoretical foes. Both ontologies are appropriate meta-frameworks for illustrating how, at individual and interactive levels with significant others, the well-being of students may be approached as they attempt to demonstrate competence in conventions associated with academic literacy.

Keywords: ontology, well-being, academic literacy, constructivism, realism

\section{INTRODUCTION}

The higher education domain in South Africa is currently experiencing numerous changes and challenges. On the one hand there are demands for curricula change and more Afrocentric content in mainstream instruction from student quarters manifested in the RhodesMustFall movement; on the other hand, our universities are faced with critical problems in terms of student attrition and retention (Garuba 2015; Akojee and Nkomo 2007, 387). Students' demands for curricula transformation in their disciplinary domains caused major disruptions 
and upheavals across South African universities (Chaudhuri 2016). In terms of student success rates and according to Scott $(2009,2)$, roughly 30 per cent of all first-year students - which translates to about 25,000 students each year, drop out or do not complete their introductory year in our universities. What the demands for curricula transformation and the crisis of student attrition in South African institutions of higher education indicate is that the well-being of our students is at risk, and perhaps, is also unhealthy. Given South Africa's recent, historical transition from an apartheid state to a democratic nation, universities as social institutions are expected to contribute towards the improvement of the lives of millions of citizens who hope to exit a life of poverty and improve their socioeconomic conditions as well as those of their families (Mac-Ikemenjima 2015). This study is therefore interested in how our research endeavours, as disciplinary practitioners and teachers in higher education, may be enhanced by applying ontological frameworks specifically aimed at highlighting the interplay between students' well-being and how they apply academic literacy conventions for educational success.

\section{CONCEPTUALISING WELL-BEING}

To probe the well-being of South African students, and in the context of this study, well-being in relationship to their ability to effectively communicate via academic literacy practices, it is necessary to theoretically define the concept. Well-being is a broad and multifaceted phenomenon. It may refer to the physical, emotional and psychological fitness of a human being (La Placa, McNaught and Knight 2013, 117). Our well-being as humans is also affected by social structures which daily impact on our lives. While these are not the only social structures which impact on our well-being, they include our families, communities, our gender, race, disciplinary curricula and even the built environment (La Placa, McNaught and Knight 2013, 117). These conceptualisations of well-being are relevant to understanding the welfare of contemporary, first-year South African students. This is because increasingly, a significant proportion of students entering our universities emerge from families, communities or schools which are characterised as financially impoverished or as under-resourced (Dass-Brailsford 2005, 579). Our students, a significant proportion of whom are first-generation, tertiary entrants in their families, are therefore academically vulnerable as they are required to adapt to the university environment as a new social space. It is therefore understandable that the transition from the secondary-school environment to higher education, for many tertiary newcomers, can be a daunting experience which impacts on their well-being (Nel, Govender and Tom 2016, 384).

Mac-Ikemenjima $(2015,2)$ believes that a key variable for understanding the well-being of youth in South Africa, and elsewhere, is a critical consideration of their values. In his view, 
any measure of students' well-being should be "relevant and resonate with the values of the young people themselves" (Mac-Ikemenjima 2015, 2). This assertion is of importance to this analysis as academic literacy conventions, specifically related to writing, constitute the central mode by which students communicate their values and perspectives in their modules. As Lillis and Scott $(2007,9)$ argue, "students' written texts continue to constitute the main form of assessment and as such writing is a 'high stakes' activity in university education". Because writing is a high stakes activity in the tertiary sphere, if South African students are unable to communicate their perspectives in their disciplinary domains, their well-being is directly at risk. For black, South African students, who often apply English as a second or third language, the risks are accentuated (Webb 2002, 49-50). Not only do they have to master conventions of academic literacy as new members of the academy, they equally must demonstrate competencies in these conventions via a tongue which differs from their home language. Mkhize and Balfour $(2017,133)$ link language usage in South African universities to the notion of human rights. Their concern is that "the continued hegemony of [English and Afrikaans] undermines the language rights of other citizens as enshrined in the Constitution of the Republic of South Africa (1996) and other legislative frameworks". While this analysis does not focus on language application in relation to human rights, it does acknowledge that learning in a second or third language may adversely affect the success, and in turn, well-being of South African students. Mkhize and Balfour $(2017,134)$ agree by asserting that "at [the] higher education level, academic literacy requirements in English remain challenging and have an impact on throughput rates". This inter-relationship between unavoidable, academic literacy conventions and language utility impacts on students' well-being and is one of the central concerns of this inquiry.

\section{ACADEMIC LITERACY AS A SOCIAL PRACTICE AND WELL-BEING}

To understand how academic literacy practices bear upon the well-being of South African students, it is necessary to locate these very conventions within a broader, theoretical framework. Conceptually, this study approaches academic literacy practices as social phenomena which are not divorced from the identities and cultural makeup of our students and the social spaces in which they are applied. Gee's (1998) theory of social Discourses, which encapsulates disciplinary-based, academic literacy practices, aids in linking language use in higher education and its effect on the well-being of our students. According to Gee and Green (1998) a Discourse incorporates much more than language usage. Instead, "knowledge constructed in classrooms [...] shapes, and is shaped by, the discursive activity and social practices of members" (Gee and Green 1998, 119). These social practices, in turn, are given 
their form by the values, beliefs and principles of those agents who develop, assess and learn via them. To clarify, these agents include people, academics and students, who engage in academic literacy conventions from the standpoints of teachers and learners. The concern of this analysis, is that not all South African students emerge from social spaces, including homes, schools and communities, which have sufficiently prepared them to effectively apply unavoidable, disciplinary discourses, as manifested in written, academic literacy conventions. Indeed, as Mkhize and Balfour $(2017,134)$ stress, "the education system in South Africa has not offered sustained learning as well as acquisition opportunities for the majority of the population in more than one language throughout schooling". This reality coerces many black, South African students into a state of academic vulnerability. Such vulnerability negatively impacts on their well-being as they strive to prove themselves as competent members and communicators in their new educational homes. Malefo $(2000,43)$ associates feelings of vulnerability, or risk, with "psychological distress" as emerging from "poor academic performance". Therefore, within Gee and Green's (1998) discursive framework, when academic literacy is approached as an indispensable, communicative tool in disciplinary domains, it is understandable how the well-being of students may be harmed if they struggle or perform poorly in mastering associated conventions and practices.

The phenomenon of the efficacious impact of communicative practices in universities on the well-being of novice students is not unique to South Africa. Writing from the context of the United States, Maloney $(2003,665)$ states that "at-risk students have [less] connection to the academic community and neither the experience or confidence to attempt to mimic its conventions". In Australia, the requirement of competence in academic literacy practices for learning success was also proven to be a real challenge. Scouller et al. $(2008,168)$ highlight how issues such as language, motivation and course expectations "combine to cause deficits in academic literacy skills". For these reasons, they argue that "development of literacy skills needs to be recognised and addressed within degree programs if literacy assessment is to be taken seriously" (Scouller et al. 2008, 168). Evidently, from the above American and Australian perspectives, communicative conventions have the capacity to impede academic development, and in turn, students' well-being.

Writing towards the South African domain, Bojuwoye (2002) highlights specific conventions, associated with academic literacy, which impact on the well-being of first-year students. They include the demands of independent study, requirements of completing assignments in short periods of time, the language of instruction and difficulty in accessing appropriate information sources for critical tasks (Bojuwoye 2002, 280). The resultant experience for one student was expressed as follows: "I have the feeling that studying for a 
degree is too difficult and I may become a dropout" (Bojuwoye 2002, 280). Other students in this particular study expressed the following worries which clearly impact on their well-being:

- "I have some difficulty taking down notes".

- "I don't know how to study on my own".

- "I am not comfortable with the language of instruction" (Bojuwoye 2002, 280).

What is apparent from the above narratives is that it is impossible to dissociate the well-being of students from competency in academic literacy conventions, issues of language and the encapsulation of these variables in discourses. Bojuwoye $(2002,287)$ stresses the concern that "the demand to seek information independently may be perceived as a threat to one's self esteem as the consequences of asking for help, or making a demand for information, may lead to embarrassment, to one appearing 'stupid' or not to have grown up". Clearly, such emotions and experiences, emerging from discursive processes, are detrimental to the well-being of students as they attempt to prove themselves as worthy members of the university community. Students specifically articulated feelings of "depression, disillusionment, low self-esteem and fear of failure to meet the expectations of their families and communities" (Bojuwoye 2002, 287).

Because it is impossible to divorce the psycho-social experiences of students as they engage in academic literacy conventions, as articulated by the experts above, it is necessary, at this juncture, to further define discourses which aids in theorising how language affiliated practices may be linked to the well-being of our students.

\section{SOCIAL LITERACIES, DISCOURSES AND STUDENTS'WELL-BEING}

When considering the relationship between students' well-being and their capacity to competently apply academic literacy conventions, it is necessary to employ a theory which aids in this process. Brian Street's $(2006,2)$ ideological model of literacy aids in highlighting the social and interactive nature of literacy practices, including academic literacy. According to Street $(2006,2)$, the ideological model of literacy "posits [that literacy] is a social practice, not simply a technical and neutral skill". As such, literacy practices are "always embedded in socially constructed epistemological principles" (Street 2006, 2). This construct of literacy is significant to this analysis as first-year university students are required to adopt new ways of being and communicating to succeed with their studies. Failure to effectively do so will not only harm the academic prospects, but equally have the potential bruise their sense of wellbeing. As Street $(2006,2)$ argues, literacy is "about knowledge [because] the ways in which people address reading and writing are themselves rooted in conceptions of [...] identity and 
being”. Again, if our students fail to competently apply unavoidable, academic literacy practices, there exists a risk, as Bojuwoye $(2002,287)$ asserts above, that their self-esteem may be harmed and that they may possible negatively label themselves. Street $(2006,2)$ confirms the interplay between students' self-conception, well-being and literacy practices by stating that "the ways in which teachers and facilitators interact is already a social practice that affects the nature of the literacy being learned [...] especially the new learners and their position and their relations of power".

Gee's $(2005,76-77)$ cultural model of discourse equally aids in comprehending the association between students' well-being and language engagement in tertiary institutions. This model of discourses holds that meaning which individuals or collectives attribute to texts or social interactions is derived from their cultural values and principles (Gee 2005, 77). Within the context of higher education, what this means is that the written development of meaning may differ between an economics and management course, or, between a political science or economics course. As pertaining to student well-being, though, the cultural model of coerces us to recognise that a significant proportion of our students emerge from locations in which the capacity to develop meaning through writing was not enabling for discursive practices in the tertiary domain. Parkinson et al. $(2008,12)$ highlight numerous pre-tertiary factors which constrain students in this way. They include realities of their teachers not using textbooks to encourage critical engagement of texts, inadequate access to textbooks in students' mother tongues or English and a learning of culture of copying from the blackboard, as opposed to engagement in argumentation via writing (Parkinson et al. 2008, 12). Further compounding the discursive and structural valley which many students have to cross when engaging in academic literacy practices, is the reality that many black students are first-generation attendees of higher education in their families. Sennett et al. $(2003,107)$ emphasise that:

\footnotetext{
"The adjustment from high school to university is often particularly difficult and traumatic for first generation students. In the South African context, such first generation students are most likely to be black Africans, whose disadvantaged educational and socioeconomic circumstances, brought about through the inequities of apartheid, may indeed make them particularly vulnerable in this transition."
}

Such trauma undoubtedly impacts on the learning success and experiences of South African students who cannot avoid having to demonstrate compentencies in the types of disciplinary discourses which are practiced in universities. They emerge from structural and cultural contexts which possess ancient modes of being and knowing, but whose ways are not familiar in the tertiary domain. As Gee $(2005,77)$ states, "different cultural models of different social 
and cultural groups of people always involve competing notions of what counts as an 'acceptable' or 'valuable' person or deed". Our students, emerging from homes, schools and communities with their unique ways of fostering values, principles and knowledges, are caught in a nexus in which they are torn between two communities, two ways of being, two ways of communicating and arguing. Such a position harms the well-being of South African students as they aim to use education and knowledge to improve the livelihoods of themselves and their families. As Sennett et al. $(203,108)$ argue, "inadequate pre-university preparation may lead [...] to students experiencing high levels of anxiety and alienation from their lecturers, academic discourse, the evaluation process and the institution itself'. For these reasons, Sebolai and Huff $(2015,336)$ argue that students need to be socialised into the discourses which are employed on campus. Their perspective is that "students need to be equipped with the ability to handle discourses that typify their particular disciplines" (Sebolai and Huff 2015, 336). Failure to participate in such discourses may create a sense of exclusion from their disciplinary communities and, in turn, negatively impact on their well-being as they struggle to communicate in a manner which is acceptable to their lecturers.

\section{ONTOLOGIES AND MAPPING STUDENTS' EXPERIENCES OF WELL-BEING}

Often, researchers are required to articulate their ontological stances in their analyses. This is because they are expected to identify an ontological position which mirrors their conception of what reality or being entails. The term ontology emerges from the Greek combination of "onto" and "logos" which means study or science of being (Guarino, Carrara and Giaretta 2009, 1). Guarino et al. $(2009,1)$ further define ontology as "the branch of philosophy which deals with the nature and structure of "reality"'. Some supervisors or research proposal committees require statements, and eventually, analyses, which evidence the application of the researcher's ontological framework towards the phenomenon of their investigation (Raddon 2010). Tuli $(2010,102)$ argues that a researcher's ontological stance is an integral component of their methodology; methodology being "a research strategy that translates ontological [...] principles into guidelines that [inform research] practices“.

Ontologies are applicable for analytical attempts which aim to explore the interplay between students' well-being and the ways by which they attempt to demonstrate mastery of academic literacy practices. This is because students' experiences form a part of their realities or ontological being. Şimşek $(2009,505)$ defines ontological or subjective well-being “as one's [confident] evaluation of life in both past and future time perspectives in addition to the present". The thesis of this analysis is that the capacity of students to competently apply academic literacy practices, or their inability to do so, impacts their ontological and subjective 
being. This inquiry considered two ontological schools and how they may assist researchers in analysing the well-being of students as they endeavour to demonstrate mastery via academic literacy practices. These schools are constructivism and realism.

\section{CONSTRUCTIVIST AND REALIST ONTOLOGIES FOR APPROACHING STUDENTS’ WELL-BEING}

According to Riegler $(2001,1)$, "constructivism is the idea that we construct our own world rather than it being determined by an external reality". This statement summarises the outlook of most constructivists. Riegler $(2001,1)$ elucidates a constructivist, ontological posture by asserting that:

"We cannot transcend the horizon of our experiences. Experiences are all we can work with; out of experiences we construct the world. Thus, there are no mind-independent entities on which our cognition is based."

The above statements represent an inverse of theoretical assertions emerging from a realist ontology. According to a branch of critical realism, developed by Roy Bhaskar $(2009,13,56)$ reality exists independently of human perception or the human mind. In Bhaskar's $(2009,56)$ words, "structures and generative mechanisms of nature exist and act independently of the conditions that allow [hu]men[s] access to them".

The above perspectives related to constructivist and realist ontologies were highlighted to illustrate their key, conceptual variances. While both ontologies are applicable towards analysis of students' well-being in South Africa, oftentimes, they lead to tensions between researchers who are ontologically committed to either paradigm. An ontological commitment is the adoption by an agent or researcher of a conception of reality. Uschold and Gruninger (1996, 2), in reference to such commitments, describe ontologies as shared understandings of a domain of interest which may be used as a unifying framework to solve [...] problems. These shared understandings include worldviews consisting of concepts, definitions and their interrelationships (Uschold and Gruninger 1996, 1). The bond between these concepts in a worldview is labelled as a "conceptualisation" (Uschold and Gruninger 1996, 5). An ontology is therefore "an explicit [emphasis added] account or representation of [some part of] a conceptualisation“ (Uschold and Gruninger 1996, 5). Smith and Welty (2001, 3) further describe ontologies as

- $\quad$ catalogues

- glossaries or

- a collection of taxonomies. 
Chandrasekaran, Josephson and Benjamins $(1999,20)$ summarise the above conceptions of ontologies as knowledge bases with a "representati[ve] vocabulary for [...] specific domain[s]".

The above description of ontological functions is by no means a complete characterisation of this philosophical branch. However, in this study, it is necessary for theorising the utility which constructivist and realist ontologies offer in attempts to understand student well-being in relation to the application of academic literacy practices. Both ontologies assist in mapping and understanding the origins of students' experiences. Constructivism and realism do so from divergent perspectives; the first from the outlook that students' experiences are mind-emergent, while the second approaches these experiences as emerging from the activities of mindindependent entities.

\section{INDIVIDUALISTIC CONSTRUCTIVISM, ACADEMIC LITERACY AND WELL-BEING}

As asserted above, constructivist ontology holds that what humans perceive in the natural and social worlds emerges from the constructs of their minds. The constructivist view that reality is resultant from the human mind is approachable on two levels; the individual and the collective. According to Smith $(1998,411)$, individualistic constructivism "is often characterised as seeing [...] activity as an individual process isolated from both cultural artefacts and more knowledgeable others". Smith $(1998,412)$ also claims that when utilised to understand how humans learn, individualistic constructivism assists where conceptual "models [...] are made as if they represent what occurs in the mind of the [individual] learner". He also affirms theoretically, from within this paradigm, "one always imagines oneself in the place of the student looking out at and attempting to make sense of the experiential world" (Smith, 1998, 412). Therefore, as a research methodology, individual or personal constructivism is useful in assisting an investigator in positioning herself in the lived world of the subject, and the contexts of their literacy-based experiences. This is achieved by having access to the thoughts and narratives of students who describe their individual experiences of engaging in academic literacy conventions. An example of such an individualistic outlook is shared in Li and Casanave's (2012) study of students' development of knowledge by using additional sources. In this study, one subject states:

"I might put myself at risk in plagiarism. But I do not intend to copy thought really, I always want to use my own words to interpret and express it, but maybe the situation is not allowed it, or I just don't know the proper way of dealing with it" (Li and Casanave 2012, 170). 
In the above narrative, from within an individualistic ontological outlook the student expresses her difficulty of sourcing additional voices to build voices. As the student refers to originality and plagiarism, which are academic crimes, the ontology also highlights how a scholarly convention places the student at risk as they may fail the assignment, course or even be placed under disciplinary proceedings due to the violation. Further, as the narrative reveals the thought processes motivating the student's actions, an individualistic ontology is further justified in determining the student's motivations and concerns, which is to pass the assignment.

Hung and Nichani, $(2001,40)$, in articulating their view of individualistic constructivism, stress that such an ontology acknowledges "individual self-organization of the mind - an active cognitive reorganisation through processes such as assimilation [and] accommodation". Competency in academic writing, including the sourcing of materials, requires the aptitude of a first-year student to effectively engage in mental self-organisation, and in turn, assimilation or accommodation of new, tertiary-based practices. If first-years students are unable to effectively apply such academic literacy conventions, such as developing knowledge by engaging expert voices and sources, in an individualistic context, or ontology, they may undergo trauma as a result of failing to properly perform the skill, which in turn, negatively affects their well-being.

\section{SOCIAL CONSTRUCTIVISM, ACADEMIC LITERACY AND WELL-BEING}

While sharing the ontological outlook that reality, or being, is a phenomenon emerging from the human mind, social constructivism diverges theoretically from individualistic constructivism, discussed above. Whereas individualistic constructivism prioritises the minds of individuals as the origins of their conceptions of reality, social constructivism incorporates the agency of influential others as an indispensable component of this process. In a social constructivist, ontological framework, the interaction between an individual student and significant others is seen as having a direct bearing on their wellness as related to academic literacy practices. This is because, according to a social constructivist ontology, for the individual mind to perceive and make sense of the social environment, including universities, it must interact with others, including lecturers, peers, librarians, tutors, etc. Specifically with reference to linguistic practices, Adams $(2006,246)$ asserts that, "due to the mediatory features of language and other forms of communication, knowledge constructs are formed first on an inter-psychological level (between people) before becoming internalised or existing intrapsychologically". In this vein, knowledge associated with academic literacy practices is first derived by interactions between students and others, and then is applied on an individualistic 
plan. The well-being of our students is therefore dependent on their ability to effectively interact with others for learning purposes. This conception correlates with Street's $(2006,2)$ conception of the ideological model of literacy, for as he states, literacy "is always embedded in social practices, such as those [of] a particular educational context”.

Fleury and Garrison $(2014,20)$ proclaim that "social constructivism involves a philosophical [ontology] wherein mind and self are contingent, emergent, and evolving, even if relatively stable [on] social constructions". They conceive of culture and social participation as mechanisms which enable students to develop within their disciplinary domains (Fleury and Garrison 2014, 20). Culture, within a social constructivist outlook, adhesively binds collectives of humans in how they interact with each other and the natural environment. Humans create meaning, even ontological beliefs, via “cultural participation” (Fleury and Garrison 2014, 20). The perspective of this study is that institutions of higher learning, including academic departments, constitute cultural domains. If our students, especially those who are firstgeneration entrants into academia, or those who emerge from under-resourced families, communities or schools, are unable to acculturate to these social spheres, including academic literacy practices, their well-being will be at risk. For as Vygotsky declares, "learner construction of knowledge is the product of social interaction, interpretation and understanding" (Adams 2006, 245). This theory is applicable towards our understanding of how first-year students come to master, or struggle with conventions associated with academic literacy; for it is senior academics, who are more experienced in knowledge construction via rhetorical practices, who establish the traditions and standards for how academic texts should be constructed. Students often model their modes of expression on what their teachers demonstrate or expect of them. Further, senior academics fulfil the role of inducting students into the ways by which knowledge is constructed through writing. These pedagogic practices evidence a social relationship between the two parties; teacher and student. Adams (2006, 246), further asserts that "the creation of knowledge cannot be separated from the [...] environment in which it is formed [and that] learning is [...] a process of active knowledge construction within and from social forms and processes". In relationship to conceptualising the development of students as academic writers, and the intertwining of their well-being in this process, academic departments and disciplines fulfil the function of social forms, while the metaphor of processes could be connected to practices such as effective structuring of texts, referencing voices of experts and avoiding plagiarism. It is therefore critical for students to be conscious of those values and principles which give form to the ways by which academic literacy practices are applied in the disciplinary communities. A lack of awareness of these values, which is cultivated through meaningful interaction with senior lecturers, may lead them 
to experience cultural dissonance, and in turn, negative experiences of well-being.

\section{REALIST ONTOLOGICAL APPROACHES TO ACADEMIC LITERACY AND WELL-BEING}

Realist ontologies articulate a view of being, or reality, which contrasts constructivist thought. Unlike constructivism which holds that being, or reality, is a mind-emergent phenomenon, realism stresses that there is an independent reality which is not reliant on either the cognitive functions of individual humans, or their social interactions with each other. There are numerous branches of the realist school. While it is impossible to list them all here, they include critical, social, experimental and naturalistic paradigms (Vihalemm 2011, 47). Vihalemm $(2011,50)$ asserts that "one cannot speak of a position as realist in [the] philosophy of science without accepting [the] thesis" of a mind-independent reality. This study will focus on two, interrelated schools of realism and their implications for research into academic literacy and how they may enhance our understanding of students' well-being.

\section{CRITICAL REALIST ONTOLOGY AND STUDENTS' WELL-BEING}

The first branch of realism to be theorised, which was developed by Roy Bhaskar, is the root of the second, which is Margaret Archer's social realism. According to Scott $(2005,634)$ critical realism is an effective tool for empirical research, such as focuses on students' well-being, because it is simultaneously able to provide a meta-theory which embraces both epistemological and ontological elements. While epistemology aids researchers in illustrating the ways of knowing of their subjects, the ontology provides a broader framework within which their experiences or attempts to know may be mapped. This theory is applicable towards understanding how students come to know academic literacy conventions within the university as a broader domain. Another advantage of a critical realist ontology is that it assists researchers in distinguishing between "individual self-determination and social context" (Scott 2005, 634). Scott $(2005,634)$ distinguishes between these two variables by associating the first with agency and the second with social structures. In the context of this analysis, a critical realist ontology may aid researchers in navigating the agency of students as they attempt to demonstrate mastery of academic literacy practices in the broader, university structures. Effectively, a critical realist ontology, given Scott's description, can simultaneously achieve the functions of both individualist and social constructivism, which separately aim to discern and conceptualise the role of individuals and collectives in empirical phenomena.

In the framework of Bhaskar's, critical realist ontology, reality consists of three domains. These are the empirical domain (location of human experiences), the actual domain (containing events) and the real domain, consisting of generative mechanisms, which Bhaskar $(2008,13)$ 
perceives to produce events and in turn, our experiences of them. This ontology is illustrated below.

\begin{tabular}{|l|l|}
\hline Domain & Corresponding phenomena \\
\hline Empirical & Experiences \\
\hline Actual & Events \\
\hline Real & Generative mechanisms \\
\hline
\end{tabular}

In a critical realist ontology, all social events, including teaching, learning or participation in literacy or discursive practices, emerge due to the powers of generative mechanisms. These are viewed as possessing "causal powers" which can produce events, and subsequently, empirical experiences (Henfridsson and Bygstad 2013, 909). In the outlook of this analysis, a critical realist ontology is therefore useful in identifying those mechanisms which enable or constrain the ability of students to effectively master conventions of academic literacy. Once these mechanisms are identified, researchers may further probe the causes of the well-being, or the lack thereof. This is where Archer's construction of a social realist is effective. In Archer's viewpoint, within the sphere of the social world, the generative mechanisms of human events, and in turn, our experiences of them, emerge due to the causal powers of social structures, human culture and agency (Boughey 2012, 63).

\section{SOCIAL REALIST ONTOLOGY AND STUDENTS' WELL-BEING}

In a social realist ontology, social structures, culture and agency possess powers which enable the emergence of actual events, and then, human experiences of them. Archer $(1982,458)$ names the emergence of social events and human experience from generative mechanisms as morphogenesis. Archer's theory of morphogenesis and emergence, in the perspective of this study, has relevance to research into how students' well-being may be effected by the interplay of social structures, culture and agency. This is because, given South Africa's diverse, ethnic and cultural population, our students emerge from a myriad of social origins. Their well-being, as they engage academic literacy practices, is determined by multiple configurations of social elements. A social realist ontology, illustrated below, is therefore able to consider, within the context of South African higher education, what Mdepa and Tshiwula $(2012,19-20)$ describe as "a system [...] of participants from different gender, race, ethnic, class and religious backgrounds".

Gender, race, ethnicity and class are social structure, which in a social realist ontology, feed into how students attempt to master academic literacy conventions. Likewise, students' 
religious affiliations, as well as the values systems they bring to the university, constitute cultures, which, like social structures, also generate varying experiences of competency, and well-being, in engaging academic literacy practices. Because an increasingly, significant proportion of South African students emerge from under-resourced schools, communities and families in which they are first-generation entrants into higher education, the combinations of culture, structure and their agency may not be sufficiently enabling for their mastery of literacybased events and practiced. Such experiences, in turn, may lead to experiences of what Bojuwoye $(2002,278)$ describes as "helplessness, a sense of loss and [...] negative self-image in some students". What a social realist ontology illustrates, is that development of students as academically literate participants, requires acknowledgement that their cultural identities and diversity of social capital feed into the ways by which their well-being is impacted, and further, how they attempt to master practices which are common to senior members on campus.

\begin{tabular}{|l|l|}
\hline Domain & Corresponding phenomena \\
\hline Empirical & Experiences \\
\hline Actual & Events \\
\hline Real / Generative mechanisms & Social structures, culture and human agency \\
\hline
\end{tabular}

Both critical and social realist ontologies have implications for research towards student development in conventions associated with academic literacy and their well-being. However, unlike individualistic or social constructivist ontologies which hold that reality emerges from either the individual mind or from the interaction between multiple minds, realism stresses that there are mind-independent entities, namely structures, cultures and agency, which give form to experiences students undergo as they attempt to demonstrate competency in rhetorical practices associated with higher education. The cultures of disciplinary departments, faculties or the broader institution, have a direct bearing on student experiences of academic writing. Therefore, and to reiterate, in a realist ontology, it is the interplay between culture, structure and agency which either enables or constrains the ability of a student to experience mastery of academic literacy practices. The ability or inability of students to adapt to the university as a social and cultural construct may therefore uplift or constrain their sense of well-being.

It is important to note that pre-tertiary, student experiences, within a realist ontology, also have influence the ways by which learners attempt to demonstrate competence as communicators via academic literacy practices. This notion is embedded in the theory of student prior knowledge. Prior knowledge relates to knowledge which students bring to the academy, 
as derived from previous experiences in their families, pre-tertiary schooling or other vocational activities. Lin, Lin and Huang $(2011,1557)$ acknowledge that while appropriate, prior knowledge can enhance students' motivation, comprehension, and performance with regard to learning new knowledge or skills, a lack of appropriate, prior knowledge may pose a risk whereby students attempt to build new knowledge on "faulty foundations".

In South Africa, the prior-knowledge or preparedness of students is determined by various conditions. These include material, affective and academic factors (Council on Higher Education 2013, 57-59). The Council on Higher Education $(2013,59)$ notes that, "access to and success in higher education is strongly influenced by the socioeconomic background of individuals". This is especially so in the South African context where a significant cohort of black students emerge from low-income families that do not have the financial resources to support the pursuit of higher education (Council on Higher Education 2013: 57). While factors such as students' motivation, hopes and dreams are enabling factors for their academic success and the drive to succeed with academic literacy practices, their socioeconomic backgrounds remain efficacious variables in their well-being.

\section{FRIENDS OR FOES? CONSTRUCTIVIST AND REALIST ONTOLOGIES}

Until this juncture of this theoretical analysis, constructivist and realist ontologies have been explored as meta-frameworks which encapsulate what a researcher's perspective of being or reality entails; specifically, as related to approaches of how students attempt to master conventions of academic literacy in institutions of higher learning and the impact of this endeavour on their well-being. The first ontology, constructivism, perceives of being or reality as emerging from the human mind; the second, realism, perceives of reality as being mindindependent. The title of this investigation has been selected due to decisions, and possibly tensions, researchers face in selecting ontological positions in their approaches to understand student growth as academically literate members of our academies and the effect of this growth on their well-being. Such decisions and associated tensions emerge from the notion of ontological commitment. Ontological commitment is an outlook which frames how a researcher conceives of their ontological truth. Guarino, Carrara and Giaretta $(1994,560)$ state that an ontological commitment "should capture and constrain a set of conceptualisations". Constructivism and realism constitute sets of conceptualisations. Hence, Guarino et al. (1994, 560) state that "ontological commitment is a mapping between a language and something which can be called an ontology". Researchers of academic literacy, therefore, cannot avoid methodological synchronisation between their ontological views and the language they employ to increase understanding of experiences associated with how conventions of academic literacy 
and students' mastering of these impact on their well-being. In analysing academic literacy practices and their impact on students' well-being, the researcher's ontological commitment is bound to be revealed through their conception of what reality is and the language they employ.

The question remains: As ontological philosophies, must constructivism and realism be foes, or may they be friends? The perspective of this study is that they need not be approached as ontological foes. Instead, there are numerous junctures where constructivist and realist modes of analysis may be conjoined to enhance our understanding of experiences associated with academic literacy and students' well-being. Constructivism, which holds that reality emerges from the mind, and realist ontology, which asserts that reality is mind-independent, can function together. They are not incompatible methodological modes. Adams (2006, 246), in reasoning about social constructivism, states that "mediatory features of language [...] are formed first on an inter-psychological level [...] before becoming internalised or existing intrapsychologically". The assertion here is that before conceptions of self or being are internalised, they are generated by social interactions with significant others. The same theory may be applied towards realist, ontological outlooks. Sterling-Folker, $(2004,342)$, in articulating a realist-constructivist ontology, states that "lying at the heart of a realist perspective on human nature $[\ldots]$ is the observation that humans are social species". Therefore, like constructivism, realism equally acknowledges the efficacy of social elements in human conceptions of reality. The advantage of amalgamating constructivist and realist ontological outlooks, in her view, is that "realism is the study of what limits human social practices, whereas constructivism is the study of what releases them" (Sterling-Folker 2004, 341). The writer of this analysis disagrees that realism is only a study of what limits social practices. While, indeed, social structures, social agents or even culture may constrain the ability of some individuals to participate in or develop competency in social practices, including academic literacy, they, too, enable them to do so. Evidence of this is the success which academic development departments and extended degree programmes have had in enabling cohorts of students to traverse the university system.

\section{IMPLICATIONS}

Ontologies are effective, analytical tools for mapping or illustrating human experiences. They are applicable in our diagnostic attempts to develop greater understanding of the well-being of novice, university students as they attempt to demonstrate mastery of unavoidable conventions associated with academic literacy. While constructivism and realism are often perceived as ontological foes, both enable our capability to generate greater understandings of elements which impact the well-being of our students; specifically, via academic writing. Individualistic or personal, constructivist ontologies coerce us, as researchers, to consider the cognitive or inner 
processes of our students. They direct us to the thoughts and emotions of students which they may keep inside as they struggle to adapt to the university and its discursive practices. These struggles, especially for students from under-resourced schools or financially impoverished families, have the potential to harm their well-being. Realist ontologies, including a social realist construct, direct us to critically consider how social structures, including gender, race, culture or class, may enable or constrain the ability of our students to demonstrate competence in conventions of academic literacy. Like social constructivist ontologies, a social realist framework aids researcher in determining the efficacy of the above variables in events involving academic literacy, and in turn, how these events impact on the well-being of our students. Student well-being is a multifaceted phenomenon which shapes their internal worlds and how they engage the university as an and external worlds. The well-being of our students is necessary for them to succeed academically, and as critical readers and writers. Constructivism and realism, which aid in the probing of these spheres of students' lives, should therefore not be ontological foes; instead, they may be approached as theoretical friends who enable our ability to develop greater insight of those whom we teach, and hopefully, how we may nurture their well-being in the periods that they are under our instruction.

\section{REFERENCES}

Adams, Paul. 2006. Exploring social constructivism: Theories and practicalities. Education 3-13 34(3): 243-257.

Archer, Margaret S. 1982. Morphogenesis versus structuration: On combining structure and action. The British Journal of Sociology 33(4): 455-483.

Bhaskar, Roy. 2009. A realist theory of science. New York: Routledge.

Bojuwoye, O. 2002. Stressful experiences of first year students of selected universities in South Africa. Counselling Psychology Quarterly 15(3): 277-290.

Boughey, Chrissie. 2012. The significance of structure, culture and agency in supporting and developing student learning at South African universities. Alternative access to higher education: Underprepared students or underprepared institutions: 62-88.

Chandrasekaran, B., John R. Josephson and V. Benjamins. 1999. What are ontologies, and why do we need them? IEEE Intelligent Systems: 20-26.

Chaudhuri, Amit. 2016. The Guardian. 16 March. https://www.theguardian.com/uk-news/2016/ mar/16/the-real-meaning-of-rhodes-must-fall (Accessed 22 July 2017).

Council on Higher Education. 2013. A proposal for undergraduate curriculum reform in South Africa. Educational, Pretoria: Council on Higher Education.

Dass-Brailsford, Priscilla. 2005. Exploring resiliency: Academic achievement among disadvantaged black youth in South Africa. Psychological Society of South Africa: 574-591.

Department of Justice and Constitutional Development. 1996. The Constitution of the Republic of South Africa. Claremont: Juta.

Fleury, Stephen, and Jim Garrison. 2014. Toward a new philosophical anthropology of education: Fully considerations of social constructivism. Interchange 45(1-2): 19-41.

Garuba, Harry. 2015. Mail and Guardian. 17 April. https://mg.co.za/article/2015-04-17-what-is-an- 
african-curriculum/ (Accessed 7 February 2018).

Gee, James. 2005. Social linguistics and literacies. New York: RoutledgeFalmer.

Gee, James and Judith Green. 1998. Discourse analysis, learning, and social practice: A methodological study. Review of Research in Education 23: 119-169.

Guarino, Nicola, Massimiliano Carrara and Pierdaniele Giaretta. 1994. An ontology of meta-level categories. KR 94: 270-280.

Henfridsson, Ola and Bendik Bygstad. 2013. The generative mechanisms of digital infrastructure evolution. MIS Quarterly 37(3): 907-931.

Hung, David and Maish Nichani. 2001. Constructivism and e-learning: Balancing between the individual and social levels of cognition. Educational Technology 41(2): 40-44.

La Placa, Vincent, Allan McNaught and Anneyce Knight. 2013. Discourse on well-being in research and practice. International Journal of Wellbeing: 116-125.

Li, Yongyan and Christine Pearson Casanave. 2012. Two first-year students' strategies for writing from sources: Patchwriting or plagiarism? Journal of Second Language Writing 21(2): 165-180.

Lillis, Theresa and Mary Scott. 2007. Defining academic literacies research: Issues of epistemology, ideology, and strategy. Journal of Applied Linguistics 4(1): 5-32.

Lin, Yi-Chun, Yen-Ting Lin and Yueh-Min Huang. 2011. Development of a diagnostic system using a testing-based approach for strengthening student prior knowledge. Computers \& Education 57(2): $1557-1570$.

Mac-Ikemenjima, Dabesaki. 2015. Youth wellbeing in South Africa: What dimensions should we measure. Commonwealth Youth and Development 13(1): 1-17.

Malefo, Vicky. 2000. Psycho-social factors and academic performance among African women students at a predominantly white university in South Africa. South African Journal of Psychology 30(4): $40-45$.

Maloney, Wendy Hall. 2003. Connecting the texts of their lives to academic literacy: Creating success for at-risk first-year college students. Journal of Adolescent \& Adult Literacy 46(8): 664-673.

Mdepa, Wandisile and Lullu Tshiwula. 2012. Student diversity in South African higher education. Widening Participation and Lifelong Learning 13(1): 19-33.

Mkhize, D. and R. Balfour. 2017. Language rights in education in South Africa. South African Journal of Higher Education 31(6): 133-150.

Nel, Kathryn, Saraswathie Govender and Reyagalaletsa Tom. 2016. The social and academic adjustment experiences of first-year students at a historically disadvantaged peri-urban university in South Africa. Journal of Psychology in Africa: 384-389.

Parkinson, Jean, Leonora Jackson, Tamlin Kirkwood and Vasanthie Padayachee. 2008. Evaluating the effectiveness of an academic literacy course: Do students benefit? Per Linguam: A Journal of Language Learning = Per Linguam: Tydskrif vir Taalaanleer 24(1): 11-29.

Raddon, Arwen. 2010. Early stage research training: Epistemology and ontology in social science research. Generic Skills Training for Research Students.

Riegler, Alexander. 2001. Towards a radical constructivist understanding of science. Foundations of Science: $1-30$.

Scott, David. 2005. Critical realism and empirical research methods in education. Journal of Philosophy of Education 39(4): 633-646.

Scott, Ian. 2009. First-year experience as terrain of failure or platform for development? Critical choices for higher education. Focus on first-year success: Perspectives emerging from South Africa and beyond: $17-36$.

Scouller, Karen, Helen Bonanno, Lorraine Smith and Ines Krass. 2008. Student experience and tertiary expectations: Factors predicting academic literacy amongst first-year pharmacy students. Studies in Higher Education 33(2): 167-78. 
Sebolai, Kabelo and Lindsay Huff. 2015. Academic literacy curriculum renewal at a South African university: A case study. Journal for Language Teaching: 333-351.

Şimşek, Ömer Faruk. 2009. Happiness revisited: Ontological well-being as a theory-based construct of subjective well-being. Journal of Happiness Studies 10(5): 505-522.

Sennett, Justin, Gillian Finchilescu, Kerry Gibson and Rosanna Strauss. 2003. Adjustment of black students at a historically white South African university. Educational Psychology 23(1): 107-116.

Smith, Erick. 1998. Social constructivism, individual constructivism and the role of computers in mathematics education. The Journal of Mathematical Behavior 17(4): 411-425.

Smith, Barry and Christopher Welty. 2001. Ontology: Towards a new synthesis. Formal Ontology in Information Systems 10(3): 3-9.

Sterling-Folker, Jennifer. 2004. Realist-constructivism and morality. International Studies Review 6(2): 341-343.

Street, Brian. 2006. Autonomous and ideological models of literacy: Approaches from new literacy studies. Media Anthropology Network 17: 1-15.

Uschold, Mike and Michael Gruninger. 1996. Ontologies: Principles, methods and applications. Knowledge Engineering Review: 1-63.

Vihalemm, Rein. 2011. Towards a practical realist philosophy of science. Baltic Journal of European Studies 1(1): 46-60.

Webb, Vic. 2002. English as a second language in South Africa's tertiary institutions: A case study at the University of Pretoria. World Englishes 21(1): 49-61. 